\title{
Nilai karakter novel Sebelas Patriot karya Andrea Hirata
}

\author{
Sarmin ${ }^{1}$, Agus Budi Santoso ${ }^{2}$ \\ 1,2) Universitas PGRI Madiun, Jl. Setiabudi No. 85 Madiun \\ e-mail: ${ }^{1)}$ sarminf20@gmail.com; ${ }^{2)}$ agusbudisantoso_pbsi@unipma.ac.id
}

\begin{abstract}
Abstrak
Penelitian ini bertujuan untuk mendeskripsikan bentuk nilai karakter yang terdapat dalam novel Sebelas PatriotkaryaAndrea Hirata. Jenis penelitian yang digunakan adalah menggunakan penelitian deskriptif kualitatif. Sumber data yang digunakan adalah sumber data primer dan sumber data sekunder. Teknik pengumpulan data pada penelitian ini dengan menggunakan dokumentasi, observasi; dan wawancara. Validitas data dalam penelitian ini menggunakan teknik triangulasi sumber data. Hasil penelitian menunjukkan bahwaNovel Sebelas Patriot karya Andrea Hirata terdapat nilai: (a) toleransi, (b) kreatif, (c) kerja keras, (d) rasa ingin tahu, (e) cinta tanah air, (f) bersahabat dan komunikatif, (g) disiplin, (h) tanggung jawab, (i) jujur, (j) cinta damai, (k) semangat kebangsaan, (I) peduli sosial, (m) mandiri, (n) menghargai prestasi, dan (o) religius yang dapat diteladani serta ditanamkan kepada siswa.
\end{abstract}

Kata kunci: nilai karakter, novel Sebelas Patriot

\section{Character values in Andrea Hirata's novel Sebelas Patriot}

\begin{abstract}
This study aims to describe the character values in Andrea Hirata's novel Sebelas Patriot. This study used descriptive qualitative method. The data source consistedprimary and secondary data. Data collection techniques were documentation, observation, and interview. Validity of the data in this study was triangulation techniques data sources. The resultof the study reveals that Andrea Hirata's novel Sebelas Patriotconsists of (a)values of tolerance (b) creative value, (c) the value of the work, (d) curiosity value, (e) the value of patriotism, (f) valuesof friendly and communicative, (g) the value of disipline, (h) value of responsibility, (i) value of honesty, (j) value of piece loving (k) value of national spirit, (I)value of social care, $(\mathrm{m})$ value of independency, ( $n$ ) value of the achievements, and (o) value of religius which can be exemplified and given to the student.
\end{abstract}

Keywords: character value, novel Sebelas Patriot

\section{Pendahuluan}

Karya sastra mengungkapkan bermacam-macam permasalahan kehidupan manusia, diantaranya adalah masalah psikologis, sosiologis, sejarah dan agama. Permasalahan itu dituangkan oleh sastrawan dengan bahasa sebagai medianya. Karya sastra melahirkan suatu kreasi yang indah dan berusaha menyalurkan kebutuhan keindahan manusia serta menjadi wadah penyampai ide-ide yang dipikirkan dan dirasakan oleh sastrawan.

Karya sastra mengandung penerapan karakter dalam sikap dan tingkah laku para tokoh. Karakter merupakan nilai-nilai perilaku manusia yang berhubungan dengan Allah SWT dan sesama manusia yang terwujud dalam pikiran, sikap, perasaan, perkataan dan perbuatan berdasakan norma-norma agama, hukum, tata krama, kultur 
serta adat-istiadat. Nilai-nilai yang termuat dalam karya satra sangat beragam, misalnya nilai patriotisme dan nilai karakter.

Nilai pendidikan karakter saat ini adalah hal yang sangat penting bagi terciptanya kesadaran moral yang tinggi dan pembenahan budaya serta karakter positif bangsa yang semakin lama semakin rapuh. Rapuhnya sebuah karakter yang mencintai budaya serta bangsa Indonesia sudah terlihat secara kasat mata. Banyakanak-anak bangsa yang tidakbangga menjadi bangsa Indonesia, sepertilebih membanggakan produk luar negeri, memberikan dukungan terhadap pertandingan negara lain dan kurangnya rasa percaya diri untuk memajukan negara Indonesia dengan kemampuan berpikir yang logis.

Warga negara sebagai manusia yang diberi kemampuan berpikir dan membedakan mana tindakan yang bermoral dan mana yang tidak. Namun banyak di antara warga negara bersikap dan berperilaku tanpa memerdulikan moral. Pada masalah ini sangat terlihat pada generasi sekarang terutama anak-anak. Saat ini tidak sulit mencari anak sekolah yang bertindak amoral (tidak bermoral). Anak pada tingkat Sekolah MenengahPertama (SMP) sudahtidak mempunyai semangat dalam belajar. Selain itu, rasa hormat yang hilang kepada orang yang lebih tua seperti menyalah gunakan kepercayaan orang tua yang telah diberikan, juga merupakan masalah moral yang terjadi pada anak dimasa sekarang. Berdasarkan uraian di atas, maka penelitian ini difokuskan pada nilai-nilai apa saja yang terkandung dalam novel sebelas patriot. Adapun tujuan penelitian ini adalah mendeskripsikan bentuknilaikarakter yang terdapatdalam novel Sebelas Patriot.

Menurut Nurgiyantoro (2012: 9), novel merupakan karya sastra yang sekaligus disebut fiksi. Bahkan dalam perkembangannya yang kemudian, novel dianggap bersinonim dengan fiksi. Dengan demikian, pengertian fiksi seperti dikemukakan di atas, juga berlaku untuk novel. Waluyo (2002: 36) menyatakan bahwa novel timbul karena pengaruh filsafat John Locke yang menekankan pentingnya fakta dan pengalaman dan memandang bahwa berpikir terlalu fantastis adalah sesuatu yang ada bahayanya. Karena pembaca-pembaca dari golongan kaya, menengah, dan terpelajar tidak menyukai puisi dan drama yang kurang realistis, maka kemudian mereka menyukai cabang kesenian sastra yang baru dan mendasarkan fakta ini.

Menurut Hariyanto (2011: 44), pendidikan karakter juga dapat didefinisikan sebagai pendidikan yang mengembangkan karakter yang mulai dari peserta didik dengan mempraktikkan dan mengajarkan nilai-nilai moral dan pengambilan keputusan yang beradap dalam hubungannya dengan Tuhannya. Dalam penelitian ini teori yang digunakan untuk mengkaji nilai karakter adalah teori menurut Zubaidi (2011: 74), yaitu 1) religius, 2) jujur, 3) toleransi, 4) disiplin, 5) kerja keras, 6) kreatif, 7) Mandiri, 8) demokratis, 9) rasa ingin tahu, 10), semangat keras, 11) cinta tanah air, 12) menghargai prestasi, 13) bersahabat atau komunikatif, 14) cinta damai, 15) gemar membaca, 16) peduli lingkungan, 17) peduli sosial dan 18) tanggung jawab.

Nilai-nilai karakter yang terdapat dalam novel Sebelas Patriot karya Andrea Hirata inilah diharapkan mampu menumbuhkan semangat patriotisme pada diri siswa lewat pendidikan karakter. Karena pendidikan karakter melalui sastra akan mempermudah siswa untuk menangkap karakter-karakter positif yang ingin ditanamkan.

\section{Metode Penelitian}

Penelitian ini menggunakan deskriptif kualitatif. Penerapan jenis penelitian deskriptif kualitatif ini dilakukan dengan langkah mendeskripsikan data yang berhubungan dengan rumusan masalah dan tujuan yang telah ditentukan. Data yang telah diperoleh kemudian dideskripsikan berupa kata-kata atau kalimat-kalimat, tentu dengan tidak mengubah makna dari data yang telah diperoleh. 
Lokasi penelitian tidak terikat. Tidak terikat saat meneliti novel. Waktu penelitian dimulai pada tanggal 2 Agustus 2016 sampai dengan tanggal 2 Januari 2017. Sumber data dalam penelitian ini yaitu sumber data primer dan sumber data skunder.

Teknik pengumpulan data yang digunakan yakni dokumentasi, observasi, dan wawancara. Penelitian ini menggunakan teknik triangulasi sumber data. Teknis analisis data yang digunakan yaitu analisis isi (content analysis). Peneliti mencari bentukbentuk nilai karakter di dalam objek yang akan dianalisis yang berupa arsip atau dokumen yang berupa novel.

\section{Hasil dan Pembahasan}

Penelitian ini merupakan penelitian kualitatif yang bertujuan untuk mengetahui nilai karakter dalam novel sebelas patriot karya Andre Hirata. Kemendikbud (2012: 12), menyatakan bahwa, nilai toleransi adalah sikap atau tindakan yang menghargai perbedaan agama, suku, etnis, pendapat, sikap, dan tindakan orang lain yang berbeda dari dirinya. Nilai kreatif, yaitu berpikir dan melakukan sesuatu untuk menghasilkan cara atau hasil baru dari sesuatu yang telah dimiliki. Nilai karakter kerja keras, yaitu perilaku yang menunjukkan upaya sungguh-sungguh dalam mengatasi berbagai hambatan belajar serta menyelesaikan tugas dengan sebaik-baiknya. Nilai rasa ingin tahu, adalah sikap dan tindakan yang selalu berupaya untuk mengetahui lebih mendalam dan meluas dari sesuatu yang dipelajarinya, dilihat, dan didengar.

Nilai cinta tanah air yang dimaksud adalah cara berpikir, bersikap, dan berbuat yang menunjukkan kesetiaan, kepedulian, dan penghargaan yang tinggi terhadap bahasa, lingkungan fisik, sosial, budaya, ekonomi, dan politik bangsa. Nilai karakter bersahabat adalah tindakan yang memperlihatkan rasa senang berbicara, bergaul, dan bekerjasama dengan orang lain. Nilai karakter disiplin adalah tindakan yang menunjukkan perilaku tertib dan patuh pada berbagai ketentuan dan peraturan. Nilai karakter tanggung jawab adalah sikap dan perilaku seseorang untuk melaksanakan tugas dan kewajibannya yang seharusnya dia lakukan, terhadap diri sendiri, masyarakat, lingkungan (alam, sosial, dan budaya), negara, dan Tuhan Yang Maha Esa. Nilai jujur merupakan perilaku yang didasarkan pada upaya menjadikan dirinya sebagai orang yang selalu dapat dipercaya dalam perkataan, tindakan, dan pekerjaan. Nilai cinta damai adalah sikap, perkataan, dan tindakan yang menyebabkan orang lain merasa senang dan aman atas kehadirannya.

Nilai semangat kebangsaan adalah cara berpikir, bertindak dan berwawasan yang menempatkan kepentingan bangsa dan negara di atas kepentingan diri dan kelompoknya. Nilai peduli sosial adalah sikap dan tindakan yang selalu ingin memberi bantuan pada orang lain dan masyarakat yang membutuhkan. Nilai mandiri adalah sikap dan perilaku yang tidak mudah tergantung dalam menyelesaikan tugas-tugas. Sikap dan tindakan yang mendorong dirinya untuk menghasilkan sesuatu yang berguna bagi masyarakat, dan mengakui, serta menghormati keberhasilan orang lain. Nilai religius merupakan sikap dan perilaku yang patuh dalam melaksanakan agama yang dianutnya, toleran terhadap pelaksanaan ibadah agama lain, dan hidup rukun dengan pemeluk agama lain.

\section{Nilai Toleransi}

Adapun hasil penelitian tidak terikat yang peneliti dapatkan sebagai berikut:

Nilai toleransi, yaitu sikap atau tindakan yang menghargai perbedaan agama, suku, etnis, pendapat, sikap, dantindakan orang lain yang berbeda dari dirinya. Dalam novel Sebelas Patriot, nilai toleransi tercermin dalam sikap tokoh yang selalu menghargai sesama dan adanya suatu perilaku yang saling tolong menolong dalam untuk kaum yang membutuhkan.

\section{Nilai Kreatif.}


Nilai kreatif, yaitu berpikir dan melakukan sesuatu untuk menghasilkan cara atau hasil baru dari sesuatu yang telah dimiliki. Dalam novel Sebelas Patriot, nilai kreatif yang tercermin yaitu munculnya suatu ide atau trik dalam bermain bola untuk bisa mengecoh lawan.

\section{Nilai Kerja Keras.}

Nilai karakter kerja keras, yaitu perilaku yang menunjukkan upaya sungguhsungguh dalam mengatasi berbagai hambatan belajar serta menyelesaikan tugas dengan sebaik-baiknya. Dalam novel Sebelas Patriot, nilai kerja keras yang tergambar adalah perilaku tokoh dalam bekerja tanpa memperdulikan pekerjaan yang dijalani karena hanya berpikir mendapatkan upah untuk membeli barang yang diinginkan. Selain itu juga tergabar sikap anak-anak yang selalu bekerja keras walau harus bergelimang dengan lumpur namun mereka tetap tekun untuk bekerja, demi mendapatkan upah.

\section{Nilai Rasa Ingintahu}

Nilai rasa ingintahu, adalah sikap dan tindakan yang selalu berupaya untuk mengetahui lebih mendalam dan meluas dari sesuatu yang dipelajarinya, dilihat, dan didengar. Dalam novel Sebelas Patriot, nilai rasa ingintahu tergambar dari tokoh aku yang selalu mencaritahu sejarah perjuangan bangsa Indonesia dalam melawan penjajah.

\section{Nilai Cinta Tanah Air}

Nilai cinta tanah air yang dimaksud adalah cara berpikir, bersikap, dan berbuat yang menunjukkan kesetiaan, kepedulian, dan penghargaan yang tinggi terhadap bahasa, lingkungan fisik, sosial, budaya, ekonomi, dan politik bangsa. Dalam novel Sebelas Patriot, nilai cintatanah air tergambar pada saat rakyat Indonesia masih dijajah oleh negara lain, mereka rela terluka demi membela negara Indonesia bahkan rakyat dicambuk dan disiksa di suatu tempat yang sering dinamakan tangsi atau tempat penyiksaan.

\section{Nilai Bersahabat dan Komunikatif.}

Nilai karakter bersahabat adalah tindakan yang memperlihatkan rasa senang berbicara, bergaul, dan bekerjasama dengan orang lain. Dalam novel Sebelas Patriot, nilai bersahabat tergambar dari persahabatan antara Adriana dan tokoh Aku. Walaupun mereka berasal dari negara yang berbeda namun bisa bersahabat dengan baik, hal tersebut didukung oleh kecintaan mereka pada hobi masing-masing yaitu sepak bola.

\section{Nilai Disiplin.}

Nilai karakter disiplin adalah tindakan yang menunjukkan perilaku tertib dan patuh pada berbagai ketentuan dan peraturan. Dalam novel Sebelas Patriot, nilai disiplin digambarkan oleh tokoh dalam menaati perintah pelatih agar segala aktivitasnya menggunakan tangan kiri, tanpa memperdulikan konteks. Hal tersebut dilakukan karena ambisinya yang selalu ingin menjadi pemain PSSI.

\section{Nilai Tanggungjawab.}

Nilai karakter tanggungjawab adalah sikap dan perilaku seseorang untuk melaksanakan tugas dan kewajibannya yang seharusnya dialakukan, terhadap diri sendiri, masyarakat, lingkungan (alam, sosial, danbudaya), negara, danTuhan Yang Maha Esa. Dalam novel Sebelas Patriot, nilai tanggungjawab tercermin adanya sikap tanggungjawab tokoh Aku untuk memenuhi keinginan ayahnya yang menginginkan kaus bertuliskan tandatangan Figo. Walalupun uangnya belum mecukupi dia tidak berputus asa, melainkan terus berusaha untuk bisa mendapatkan uang agar bisa memberikan senyuman pada Ayahnya. Jadi kutipan tersebut juga mengajarkan untuk tetap yakin dan tidak boleh berputus asa melainkan harus berani dan bertanggungjawab.

\section{Nilai Jujur}


Nilai jujur merupakan perilaku yang didasarkan pada upaya menjadikan dirinya sebagai orang yang selalu dapat dipercaya dalam perkataan, tindakan, dan pekerjaan. Dalam novel Sebelas Patriot, nilai jujur terlihat dari sepenggal kalimat "dadaku mengembang dadaku bangga karena memeluk seorang patriot" karena di situ ada sikap mengatakan isi hatinya yang sebenarnya yang dirasakan oleh pembicara.

\section{Nilai Cinta Damai.}

Nilai cinta damaia dalahsikap, perkataan, dan tindakan yang menyebabkan orang lain merasa senang dan aman atas kehadirannya. Dalam novel Sebelas Patriot, nilai jujur tergambar dalam tokoh Ayah yang cenderung rendah hati dan tak mengenal kekerasan sehingga dapat memunculkan rasa nyaman dan aman pada orang lain.

\section{Nilai Semangat Kebangsaan}

Nilai semangat kebangsaan adalah cara berpikir, bertindak dan berwawasan yang menempatkan kepentingan bangsa dan negara di atas kepentingan diri dan kelompoknya. Dalam novel Sebelas Patriot, menunjukkan bahwa adanya nilai karakter semangat kebangsaan karena berhasil dalam melakukan pertandingan dan mendapkan penghargaan dalam melawan negara penjajah.

\section{Nilai Peduli Sosial.}

Nilai peduli sosial adalah sikap dan tindakan yang selalu ingin memberi bantuan pada orang lain dan masyarakat yang membutuhkan. Dalam novel Sebelas Patriot, nilai karakter peduli sosial tercermin pada tokoh Toharun yang mempunyai kebaikan untuk membantu temannya yang sedang sakit agar memiliki ketentraman jiwa.

\section{Nilai Mandiri}

Nilai mandiri adalah sikap dan perilaku yang tidak mudah tergantung dalam menyelesaikan tugas-tugas. Dalam novel Sebelas Patriot, nilai mandiri terlihat pada saat tokoh Aku akan melakukan latihan sepak bola dia bisa giat berlatih sendiri tanpa harus menunggu pelatih.

\section{Nilai Menghargai Prestasi}

Nilai menghargai prestasi adalah sikap dan tindakan yang mendorong dirinya untuk menghasilkan sesuatu yang berguna bagi masyarakat, dan mengakui, serta menghormati keberhasilan orang lain. Dalam novel Sebelas Patriot, terlihat adanya nilai menghargaiprestasi yang tercermin dari sikap tokoh pelatih Toharun yang selalu memberikan penghargaan pada anak buahnya setelah memperoleh prestasi. Jadi hal tersebut merupakan suatu bentuk cara menghargai prestasi kepada seseorang.

\section{Religius yang Dapat Diteladani.}

Nilai religius merupakan sikap dan perilaku yang patuh dalam melaksanakan agama yang dianutnya, toleran terhadap pelaksanaan ibadah agama lain, dan hidup rukun dengan pemeluk agama lain. Dalam novel Sebelas Patriot, terlihat adanya nilai religius atau sikap untuk melakukan ibadah dengan cara berdoa sesuai yang dianutnya.

Nilai karakter di atas, sejalan dengan hasil penelitian Bayu (2015), bahwa Adanya beberapa nilai pendidikan karakter yang ada di dalam novel Amelia Karya Tere Liye adalah religius, jujur, toleransi, disiplin, kerja keras, kreatif, mandiri, demokratis, rasa ingin tahu, cinta tanah air, bersahabat atau komunikatif, cinta damai, gemar membaca, peduli sosial dan tanggung jawab. Sedangkan relevansinya ada kesusuaian antara nilai pendidikan karakter dengan novel amelia dengan nilai karakter siswa anak usia madrasah ibtidaiyah.

\section{Kesimpulan}

Novel Sebelas patriot karya Andrea Hirata memiliki nilai: (1) Toleransi, (2) Nilai kreatif, (3) Nilai kerja keras, (4) Nilai rasa ingin tahu, (5) Nilai cinta tanah air, (6) Nilai bersahabat dan komunikatif, (7) Nilai disiplin, (8) Nilai tanggung jawab, (9) Nilai jujur, 
(10) Nilai cinta damai, (11) Nilai semangat kebangsaan, (12) Nilai peduli sosial, (13) Nilai mandiri, (14) Nilai menghargai prestasi, dan (15) Religius yang dapat diteladani.

Mengingat novel Sebelas Patriot karya Andrea Hirata memiliki nilai-nilai yang dapat diteladani maka perlu dikembangkan, agar generasi muda memahami danmentransformasi nilai untuk bersikap dan bertindak.

\section{Daftar Pustaka}

Harianto. (2011). Cerdas, Kritis, danAktifBerwarganegara. Jakarta: Erlangga.

Kemendikbud. (2012). Pendidikan Karakter Terintegrasi dalam Pembelajaran di Sekolah Menengah Pertama. Jakarta: Direktorat PSMP Kemdiknas.

Nurgiyantoro, B. (2012). TeoriPengkajianFiksi. Yogyakarta: PT. GadjahMada University Press.

Waluyo, H. J. (2002). PengkajianSastraRekaan.Salatiga: Widya Sari Press.

Zubaidi. (2011). Pendidikan Berbasis Masyarakat. Yogyakarta: Pustaka Belajar. 